\title{
Immune mechanisms of Theiler's virus-induced demyelination
}

\author{
Byung Suk Kim ${ }^{1,2}$ and Joann P. Palna ${ }^{1}$ \\ ${ }^{1}$ Departments of Microbiology-Immunology and Pathology, \\ Northwestern University, Medical School, Chicago, IL 60611 \\ ${ }^{2}$ Corresponding author: Tel, +1-312-503-8693; \\ Fax, +1-312-503-1339; E-mail, bskim@casbaj/acms/nwu.edu \\ Accepted 3 September 1999
}

Abbreviations: MS, multiple slerosis; TMEV, Theiler's murine encephalitis virus; TMEV-IDD, TMEV-induced demyelinating disease; CTL, cytotoxic T lymphocyte; LPS, lipopolysaccharide

\section{Introduction}

Multiple sclerosis (MS) is an immune-mediated neurological disease reflecting demyelination in the white matter of the brain and spinal cord (Adams and Victor, 1977). The clinical symptoms range from a mild nervous system disability to a severe degenerative paralyzing disorder. Generally, MS is considered to involve autoimmunity to myelin components and is one of the most common neurological disorders of young adults. It is estimated that approximately 300,000 patients are affected in the USA alone. Because of the chronic nature of the disease, social and economic loss by this disease is enormous. Although the cause of MS is unknown, one or multiple infectious agents may be involved in the initial infliction of tissue damage leading to autoimmunity. A possible viral association is suggested by epidemiological studies (Johnson, 1975; McFarlin and McFarland, 1982) as well as the detection of viral antigens and virus-specific antibodies in the majority of MS patients (Soldan et al., 1997). Several virus-induced and autoimmune models have been used to study the underlying mechanisms of this disease (Daniels et al., 1952; Alford, 1984; Dal Canto et al., 1996; Miller et al., 1997). These models include demyelinating diseases induced by infection with mouse Hepatitis virus (Lane and Buchmeier, 1997), Sindbis virus (Griffin et al., 1992), Semliki Forest virus (Smyth et al., 1990), Herpes virus (Kastrukoff et al., 1992), or Theiler's murine encephalomyelitis virus (TMEV) as well as immunization with central nervous system autoantigens. Among these experimental model systems, TMEVinduced demyelination (Dal Canto et al., 1996; Miller et al., 1997) provides an excellent infectious model for the following reasons. The viral structure of TMEV is relatively simple and only few proteins are involved in induction of immune responses. In addition, virus infection has neurotrophism and does not induce any other detec diseases except demyelination. An intracerebral inoculation of TMEV into susceptible strains of mice results in a chronic immune-mediated demyelinating disease that shares many of the features of human MS. For example, chronic pathological involvement is limited to the white matter of the CNS and myelin breakdown is directly related to the clinical symptoms. In addition, demyelination is primarily associated with cell-mediated immune responses and strong autoimmunity to myelin antigens is induced following the initial demyelination by virus-specific T cells (Miller et al., 1997).

TMEV is a common enteric pathogen in mice and belongs to the picornaviridae (Theiler and Gard, 1940; Lipton and Friedmann, 1980). Like other picornaviruses, TMEV has four structural capsid proteins (VP1, VP2, VP3 and VP4) assembled in an icosahedral structure and thus the major immune responses to the virus are against the capsid proteins (Theiler and Gard, 1940; Lipton and Friedmann, 1980). Two major subgroups of TMEV have been identified: The first subgroup includes GDVII and FA viruses causing rapid and fatal encephalitis and the second subgroup includes the BeAn and DA strains. The second subgroup causes a biphasic neurological disease upon intracerebral inoculation of the virus into susceptible mice (Dal Canto et al., 1996). The early, acute phase displays flaccid limb paralysis and degeneration of neurons. The late phase represents chronic, inflammatory demyelination.

Keywords: antigen presentation, multiple sclerosis, infectious immunity-virus, demyelination

\section{Immune responses to TMEV and disease}

Subcutaneous immunization with UV-inactivated TMEV prior to viral infection efficiently protects susceptible mice from demyelinating disease (Yahikozawa et al., 1997). In contrast, similar immunization of SJL mice after viral infection does not confer protection, but rather accelerate the disease course. These results strongly suggest that the timing of certain immune components is important in the protection and/or induction of demyelinating disease. However, because the virus contains both $B$ cell and $T$ cell epitopes, it is difficult to analyze the individual immune components involved. This diffi- 

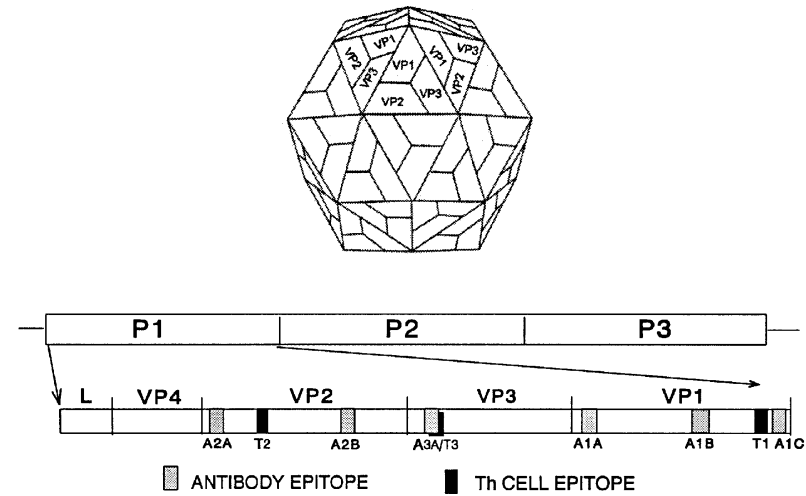

Figure 1. Viral capsid structure and the major epitopes for antibody as well as Th cells are schematically shown. VP1, VP2 and VP3 of Theiler's virus are external capsid proteins. Six major linear antibody epitopes and three Th epitopes have been found. These three Th epitopes, one on each external capsid protein, represent the great majority $(\sim 90 \%)$ of Th responses to TMEV.

culty is partly overcome by utilizing various fusion proteins containing individual viral capsid proteins or synthetic peptides representing antibody and/or T cell epitope regions. The locations of the major Th epitopes and linear antibody epitopes are diagrammatically shown in Figure 1.

\section{Effect of antibody responses}

To dissect the immune components involved in the protection and/or acceleration of demyelination upon immunization with inactivated virus, fusion proteins and synthetic peptides containing the linear antibody epitopes were utilized. Immunization with VP1 and VP2 fusion proteins prior to viral infection, but not VP3, resulted in protection from subsequent development of demyelination (Figure 2). Mice free of clinical symptoms after preimmunization with fusion proteins displayed high levels of antibodies to the capsid proteins. Further immunization with $\mathrm{KLH}$ conjugates of synthetic peptides containing individual antibody epitopes indicated that antibodies to only certain linear epitopes are protective, and such antibody-mediated protection appears to be restricted during the early stages of viral infection (Yahikozawa et al., 1997). This is consistent with previous studies indicating that antibodies to certain viral determinants display strong neutralizing properties in vitro and prevent pathogenesis in vivo following transfusion with antisera (Wada et al., 1994; Kurtz et al., 1995; Sato et al., 1996).

\section{Effect of $\mathrm{CD}^{+} \mathrm{T}$ cell responses}

Treatment with antibodies to either the class II or CD4 molecules suppressed demyelination induced by TMEV (Rodriguez et al., 1986; Welsh et al., 1987). The majority of MHC class II-restricted helper T cell lines/clones derived from demyelinating lesions of the spinal cords after viral infection reacted with VP1 or VP2 protein,

\begin{tabular}{|c|c|c|}
\hline ANTIGENS & PRE-IMMUNIZATION & POST-IMMUNIZATION \\
\hline UV-TMEV & s. & - \\
\hline B VP1 & s. & - \\
\hline VP2 & m & \\
\hline VP3 & $\theta=$ & $\theta$ \\
\hline $\mathrm{A} 1 \mathrm{~A}, \mathrm{~A} 1 \mathrm{C}$ & क &  \\
\hline A2B & anc & कב \\
\hline A3A & 20 & 2. \\
\hline TVP1 & 2 & \\
\hline & क. & क \\
\hline NONE & Dn & and \\
\hline
\end{tabular}

Figure 2. Effect of immune responses to $B$ and Th epitopes on the development of TMEV-induced demyelinating disease. Antibodies to certain epitopes are always protective but some are not. Fusion proteins with both $B$ and $T$ cell epitopes are protective when exposed prior to viral infection. On the other hand, Th responses alone are harmful, regardless of the time of virus exposure. The VP3 region containing both Th and B cell epitopes is an exception to the rule: It does not appear to play an active role in either protection or pathogenesis.

suggesting that these virus-specific Th cells in the CNS are involved in the pathogenicity (Yauch and Kim, 1994). In addition, the majority ( $90 \%)$ of T cells recognized one of three predominant epitopes (VP1 $1_{233-250 \text {, }}$ VP2 ${ }_{74-86}$ and $\left.V P 3_{24-37}\right)$, one on each major external capsid protein (Yauch et al., 1995). It is interesting to note that the VP3 Th epitope overlap with the major VP3 linear antibody epitope (Figure 1).

The $T$ cell responses to the three predominant epitopes are similar throughout the disease course without preferential response to any one epitope (Yauch et al., 1998). However, the level of IFN $\gamma$ production was highest in response to VP1, intermediate with VP2 and lowest with the VP3 epitope peptide. In contrast, the production of Th2 cytokines is highest in response to VP3 and lowest following stimulation with VP1 epitope peptides. However, it is unclear at this time whether the overlap between Th and antibody epitopes in VP3 influences the type of Th response. Further immunization with peptides demonstrated that VP1 $1_{233-250}$ and VP2 ${ }_{74-86}$ epitopes are able to exacerbate the disease while $\mathrm{VP}_{24-37}$ epitope is not. Levels of various cytokine mRNAs accumulated in the CNS and cytokines produced by $\mathrm{T}$ cell clones derived from demyelinating lesions were analyzed (Yauch and Kim, 1994; Palma et al., 1996; Yauch et al., 1998). Most of the T cell clones produced IL-2 and IFN $\gamma$, but not IL-4, suggesting that the majority of Th cells in the CNS is Th1. Interestingly, Th1 cytokine messages preceded Th2 cytokine messages in the CNS of virus-infected SJL mice, suggesting 
that the initial establishment of Th1 response is critical for the pathogenesis of TMEV-induced demyelination. Taken together, these experiments strongly suggest that the T cell responses to VP1 and VP2 are mainly the Th1 type, and are primarily involved in the pathogenesis of TMEV-induced demyel inating disease (TMEV-IDD).

To understand further the nature of the Th responses, the pathogenic $\mathrm{Th} 1$ response to the major $\mathrm{VP}_{233-250}$ epitope region has been extensively investigated (Yauch et al., 1998). The fine epitope regions recognized by individual hybridomas are broad and largely overlapping, but not identical (Kim et al., 1999). However, close to $50 \%$ of the $\mathrm{T}$ cell hybridomas reactive to $\mathrm{VP}_{233-250}$ used the $T$ cell receptor $V \beta 16$. In addition, all the $T$ cell hybridomas, recognizing the region with valine at position 245 as the C-terminal residue, expressed V $\beta 16$. Such restriction in the $V_{\alpha}$ usage among the VP1 $1_{233-250^{-}}$ specific $T$ cell hybridomas was not found. These results functionally demonstrate for the first time that recognition of the C-terminal residue of a minimal T cell epitope can be associated with a particular $\mathrm{V} \beta$ (but not $\mathrm{V} \alpha$ ) subfamily-specific sequences, resulting in highly restricted $V \beta$ repertoire of the epitope-specific T cells. Nevertheless, the $T$ cell response to a representative Th1 epitope indicates the broad diversity and complexity of the T cell repertoire towards viral determinants despite the limited number of predominant epitope regions.

\section{Role of $\mathrm{CD8}^{+} \mathrm{T}$ cell responses}

The potential role of CD8+ T cells in the pathogenesis of demyelination is controversial. A group of investigators proposed that elimination of myelin producing cells (e.g. oligodendrocytes) are necessary for clinical manifestation and this is mediated by cytotoxic T cells (CTL) which are specific for the virus-infected cells (Murray et al., 1998; Rivera-Quinones et al., 1998). However, other groups have demonstrated that treatment with anti-CD8 antibodies does not alter the course of TMEV-IDD (Borrow et al., 1992). In addition, viral infection can lead to clinical symptoms even in $\beta_{2}$-microglobulin-deficient mice, lacking functional $\mathrm{CD}^{+} \mathrm{T}$ cells (Pullen et al., 1991; Fiette et al., 1993). Moreover, a high level of CTLs is found in resistant mice and a low level in susceptible mice (Dethlefs et al., 1997). The inconsistent level of virus-specific CTLs in susceptible SJL mice may reflect a poor CD8+ T cell response (Lin et al., 1998; Lindsley et al., 1991). Also, adoptive transfer of $\mathrm{CD}^{+} \mathrm{T}$ cells confers resistance to TMEV-IDD in the susceptible recipient mice (Nicholson et al., 1996), supporting the protective (rather than pathogenic) role of $\mathrm{CD} 8^{+}$CTLs. Furthermore, $\beta_{2}$-microglobulin-deficient mice with susceptible SJL background are also susceptible to the development of demyelinating disease strongly suggesting that such virus-specific CTLs are not involved in the pathogenesis of demyelination (Yauch and Kim, unpublished observation). Therefore, the major role of virus-specific CTLs is viral clearance for the protection rather than tissue damage leading to clinical symptoms, in contrast to the published hypothesis (Rivera-Quinones et al., 1998).

\section{Cytokine manipulation and disease course}

The potential involvement of key cytokines for the Th1 response to virus was explored as it is apparently associated with the pathogenesis of demyelination. To examine the potential role of IFN $\gamma$, anti-IFN $\gamma$ antibody was administered to virus-infected mice. These treated mice displayed significantly accelerated disease course and enhanced Th1 responses towards viral antigens (Pullen et al., 1994; Rodriguez et al., 1995). However, mice that received recombinant IFN $\gamma$ intracerebrally also demonstrated a similar acceleration of disease. Interestingly, virus-induced demyelination is also accelerated in IFN $\gamma$ receptor deficient mice, suggesting that IFN $\gamma$ is not necessary for developing demyelination and perhaps other proinflammatory cytokines such as TNF $\alpha$ may be able to replace the cytokine function (Fiette et al., 1995). Potential effects of other cytokines on TMEV-induced demyelination have also been investigated. For example, antibodies to TNF $\alpha$ or IL-12 (Inoue et al., 1996; Fushimi et al., 1998; Inoue et al., 1998), as well as administration of IL-4 (unpublished observation), were able to significantly delay the development and reduce the severity of TMEV-induced demyelination. However, the timing of treatment with respect to viral infection may be critical for the prevention and/or amelioration of disease (Inoue et al., 1998; Bright et al., 1999). These results strongly suggest that proinflammatory cytokines resulting from the Th1 response to the virus are responsible for the pathogenesis of demyelination, as seen with MS (Benvenuto et al., 1992; Correale et al., 1995; Rieckmann et al., 1995). Such parallelism between the virus-induc-ed demyelination and human MS makes this system very attractive for studying the underlying mechanisms involved in the maintenance of the Th1/Th2 balance.

\section{Response to low-pathogenic variant virus}

Non-pathogenic variant viruses have also been utilized to understand the pathogenic mechanisms instigated by the virus. Several forced mutant viruses resistant to antiviral antibodies or recombinant viruses between viruses resulting in chronic and non-chronic infections have been used to analyze the nature of the virus-induced demyelination (Zurbriggen and Fujinami, 1989; Bureau et al., 1993; Pritchard et al., 1993). However, these variant viruses are not naturally occurring and thus it is difficult to evaluate the significance of the results. On the 
other hand, a spontaneous non-pathogenic variant displayed a single substitution of lysine to arginine at position 244 within the VP1 $1_{233-250}$ epitope, which is the only amino acid difference found in the $\mathrm{P} 1$ region encoding all of the capsid proteins (Kim et al., 1998). In addition, the majority of Th cells specific for VP1 $1_{233-250}$ from mice infected with the pathogenic wild-type virus is Th1 type. Conversely, the major $T$ cell population specific for VP1 $1_{\text {K244R }}$ from the variant virus-infected mice is Th2 type. Furthermore, the overall $\mathrm{T}$ cell response to the variant virus is primarily Th2 type, whereas that induced after infection with the wild type is Th1 type (Figure 3). Thus, such a spontaneous single amino acid change in a predominant Th epitope of a viral coat protein may exert a profound impact to the type of host immune response and the consequent pathogenesis of virally induced immune-mediated diseases. Moreover, such spontaneous non-pathogenic variants of TMEV may occur more frequently than previously thought.

\section{Viral persistence and inflammatory responses}

Using various recombinant viruses, it has previously been established that chronic demyelination is associated with the ability of virus to persist in the CNS (Bureau et al., 1993; Pritchard et al., 1993). These studies provided valuable information regarding the structural sites involved in viral persistence. However, the location on the viral genome involved in persistence has been controversial. Interestingly, administration of bacterial lipopolysaccharide (LPS), a potent inducer for non-specific inflammatory response, concomitant with viral infection in resistant C57BL/6 mice resulted in enhanced viral persistence, Th responses to viral antigens and subsequent clinical symptoms (Pullen et al., 1995). Similar enhancement of viral persistence and

\section{PATHOGENIC} VIRUS

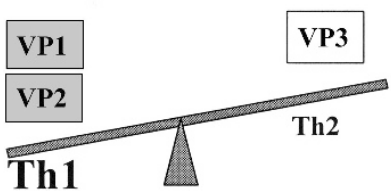

Demyelination

\section{LOW-PATHOGENIC VIRUS}

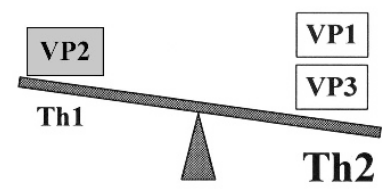

No Demyelination
Figure 3. Potential immunological mechanisms for differential pathogenesis between the pathogenic parental virus and low-pathogenic variant virus. The pathogenic virus contains two Th1-inducing epitopes and one Th2inducing epitope. A mutation in one of theTh1-inducing epitopes converts it to a Th2-inducing epitope tipping the overall balance favoring non-pathogenic Th2 responses. pathogenicity of a low-pathogenic variant was observed after treatment with LPS (Palma et al., 1996). These results strongly suggest a possibility that an increase in the inflammatory response in the CNS may prolong viral persistence and further amplify the Th1 response.

\section{Potential mechanisms}

Several hypotheses have been proposed to explain virusinduced demyelination. These include: 1) "bystander" damage of myelin (Wisniewski and Bloom, 1975; Clatch et al., 1986) as a consequence of the inflammatory Th1 response against TMEV antigens, 2) induction of autoimmunity (epitope spreading) to the myelin proteins released by viral damage to the CNS (Miller et al., 1997), and/or 3) direct elimination of myelin producing cells (e.g. oligodendrocytes) by cytotoxic $T$ cells (CTL) specific for the virus-infected cells (Rivera-Quinones et al., 1998). Among these, the "CTL" hypothesis is the least consistent with various experimental results as discussed earlier. The "bystander" hypothesis favors the involvement of virus-reactive Th1 cells, which activate macrophages resulting in demyelination. The involvement of virus-specific Th1 responses in the pathogenesis of demyelination is supported by strong experimental data. In addition, the fact that autoimmune responses to the major myelin components are followed by the initial inflammatory response to viral antigens supports the potential involvement of "epitope spreading" in the pathogenesis of demyelination (Miller et al., 1997). However, the degree of contribution of this autoimmunity to the manifestation of overall demyelinating disease is not yet clear, since the clinical signs of demyelination are detected prior to the detection of autoimmunity. In addition, it is difficult to discern at this time that such epitope spreading involves the mechanisms of molecular mimicry with potential cross-reactivity between autoantigens and viral epitopes.

Nevertheless, the local presentation of viral epitopes to infiltrating $\mathrm{CD}^{+} \mathrm{T}$ lymphocytes in the CNS may be a critical step for initiation and propagation of the immunopathologic tissue damage following viral infection (Figure 4). MHC class II Ags can be expressed on neuroglia cells following exposure to pro-inflammatory cytokines such as IFN $\gamma$ (Wong et al., 1984), or virus particles (Massa et al., 1986). For example, cytokineactivated astrocytes further activate virus-specific, CD4 ${ }^{+}$ $\mathrm{T}$ cells and, consequently undergo Fas-mediated apoptosis by the activated T cells in vivo as well as in vitro (Palma et al., 1999). Since astrocytes play an integral role in maintaining the blood brain barrier (Eddleston and Mucke, 1993; Montgomery, 1994), such an apoptosis of astrocytes most likely contributes to the pathogenesis of TMEV-induced demyelination. This is consistent with previous studies suggesting the role of Fas- 


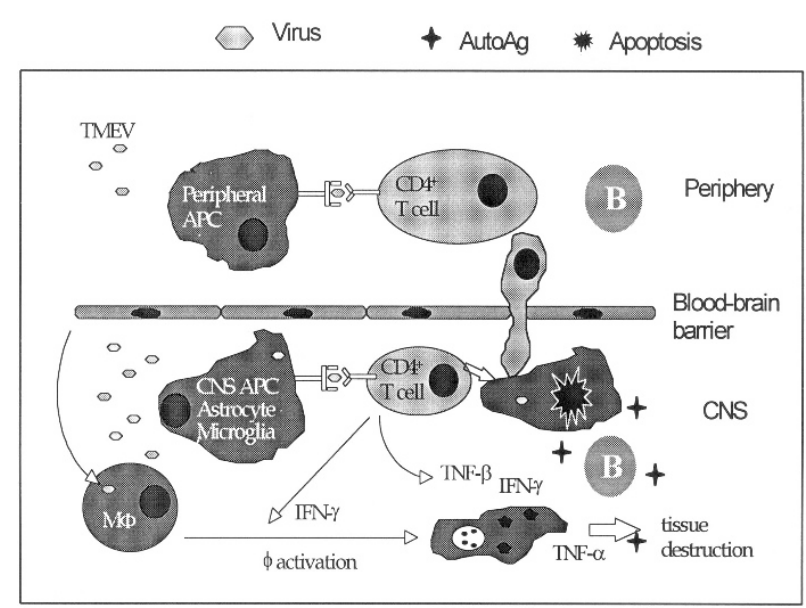

Figure 4. Potential pathogenic mechanisms involved in the immune-mediated demyelination induced following TMEV infection. Resident glial cells may also be activated by inflammatory cytokines and become competent antigen presenting cells that further stimulate inflammatory Th1 cell response in the CNS. Such T cell activation may consequently lead to breaching the blood brain barrier by cytokines and/or apoptosis of CNS cells. The tissue destruction lead to further release of autoantigens facilitating autoimmunity.

FasL interaction in multiple sclerosis (Dowling et al., 1996) and similarly in autoimmune mouse models of demyelination (Malipiero et al., 1997; Sabelko et al., 1997; Waldner et al., 1997). In addition, it is known that activated astrocytes produce a variety of immunoregulatory cytokines (Wesselingh et al., 1990; Lee et al., 1993), chemokines attracting various inflammatory cells (Tani et al., 1996), as well as adhesion and co-stimulatory molecules (Shrikant et al., 1995; Nikcevich et al., 1997). Similarly, virus infection itself may also activate a variety of genes, including chemokines, involved in the immune response. These may promote the influx of inflammatory cells into the CNS further promoting the immunopathological reactions of the CNS leading to immune-mediated demyelination. The initial tissue damage by these virus-specific Th1 cells may facilitate release of abundant CNS autoantigens to the highly inflammatory environment resulting in a vigorous autoimmune response. The ability of direct lysis of the host cells by this virus may also contribute to the release of autoantigens. Therefore, a precise understanding of the pathogenic mechanisms involved in this virus-induced demyelinating disease may provide important general implication regarding the initiation and progression of many different tissue-specific autoimmune diseases such as arthritis and diabetes.

\section{Acknowledgement}

This work was supported by United States Public Health Service Grants, RO1 NS28752, RO1 NS33008, and PO1 NS23349.

\section{References}

Adams, R. and Victor, M. (1977) "Principles of Neurology". McGraw Hill, New York

Alford, E. C. (1984) "Experimental allergic encephalomyelitis: a useful model for multiple sclerosis". (E. C. Alvord, Kies, M.W., and Suckling, A.J., Ed.) A.R. Liss, New York

Benvenuto, R., Paroli, M., Buttinelli, C., Franco, A., Barnaba, V., Fieschi, C. and Balsano, F. (1992) Tumor necrosis factoralpha and interferon-gamma synthesis by cerebrospinal fluidderived T cell clones in multiple sclerosis. Ann. N. Y. Acad. Sci. 650: $341-6$

Borrow, P., Tonks, P., Welsh, C. J. and Nash, A. A. (1992) The role of $\mathrm{CD} 8+\mathrm{T}$ cells in the acute and chronic phases of Theiler's murine encephalomyelitis virus-induced disease in mice. J. Gen. Virol. 73: 1861-5

Bright, J. J., Rodriguez, M. and Sriram, S. (1999) Differential influence of interleukin-12 in the pathogenesis of autoimmune and virus-induced central nervous system demyelination. $J$. Virol. 73: 1637-9

Bureau, J. F., Montagutelli, X., Bihl, F., Lefebvre, S., Guenet, J. L. and Brahic, M. (1993) Mapping loci influencing the persistence of Theiler's virus in the murine central nervous system. Nature Genet. 5, 87-91

Clatch, R. J., Lipton, H. L. and Miller, S. D. (1986) Characterization of Theiler's murine encephalomyelitis virus (TMEV)specific delayed-type hypersensitivity responses in TMEVinduced demyelinating disease: correlation with clinical signs. J. Immunol. 136: 920-927.

Correale, J., Gilmore, W., McMillan, M., Li, S., McCarthy, K., Le, T. and Weiner, L. P. (1995) Patterns of cytokine secretion by autoreactive proteolipid protein- specific $T$ cell clones during the course of multiple sclerosis. J. Immunol. 154: 2959-68.

Dal Canto, M. C., Kim, B. S., Miller, S. D., Melvold, R. W. (1996) Theiler's murine encephalomyelitis virus (TMEV)induced demyelination: a model for human multiple clerosis. Methods 10: 453-461

Daniels, J. B., Pappenheimer, A. M. and Richardson, S. (1952) Observations on encephalomyelitis of mice (DA strain). J. Exp. Med 96: 517.

Dethlefs, S., Brahic, M. and Larsson-Sciard, E. L. (1997) An early, abundant cytotoxic T-lymphocyte response against Theiler's virus is critical for preventing viral persistence. J. Virol. 71: 8875-8

Dowling, P., Shang, G., Raval, S., Menonna, J., Cook, S. and Husar, W. (1996) Involvement of the CD95 (APO-1/Fas) receptor/ligand system in multiple sclerosis brain. J. Exp. Med. 184: $1513-8$

Eddleston, M. and Mucke, L. (1993) Molecular profile of reactive astrocytes--implications for their role in neurologic disease. Neuroscience 54: 15-36

Fiette, L., Aubert, C., Brahic, M. and Rossi, C. P. (1993) Theiler's virus infection of beta 2-microglobulin-deficient mice. J. Virol. 67: 589-92

Fiette, L., Aubert, C., Muller, U., Huang, S., Aguet, M., Brahic, 
M. and Bureau, J. F. (1995) Theiler's virus infection of 129Sv mice that lack the interferon alpha/beta or interferon gamma receptors. J. Exp. Med. 181: 2069-76

Fushimi, T., Inoue, A., Koh, C. S., Yamazaki, M., Ishihara, Y. and Kim, B. S. (1998) The effect of pentoxifylline (PTX) on Theiler's murine encephalomyelitis (TMEV)-induced demyelinating disease. Cell. Immunol. 186: 140-6

Griffin, D. E., Levine, B., Tyor, W. R. and Irani, D. N. (1992) The immune response in viral encephalitis. Semin. Immunol. 4: $111-9$

Inoue, A., Koh, C. S., Yahikozawa, H., Yanagisawa, N., Yagita, H., Ishihara, Y. and Kim, B. S. (1996) The level of tumor necrosis factor-alpha producing cells in the spinal cord correlates with the degree of Theiler's murine encephalomyelitis virus-induced demyelinating disease. Internat. Immunol. 8: $1001-8$

Inoue, A., Koh, C. S., Yamazaki, M., Yahikozawa, H., Ichikawa, M., Yagita, H. and Kim, B. S. (1998) Suppressive effect on Theiler's murine encephalomyelitis virus-induced demyelinating disease by the administration of anti-IL-12 antibody. J. Immunol. 161: 5586-93

Johnson, R. T. (1975) The possible viral etiology of multiple sclerosis. Adv. Neurol. 13: 1-46

Kastrukoff, L. F., Lau, A. S., Leung, G. Y., Walker, D. G., Thomas, E. E. and Walker, D. (1992) Herpes simplex virus type I (HSV I)-induced multifocal central nervous system (CNS) demyelination in mice [erratum in $\mathrm{J}$ Neuropathol Exp Neurol 1992 Nov; 51(6): 658]. J Neuropathol. Exp. Neurol. 51: 432-9

Kim, B. S., Bahk, Y. Y., Kang, H. K., Yauch, R. L., Kang, J. A., Park, M. J. and Ponzio, N. M. (1999) Diverse fine specificity and receptor repertoire of $T$ cells reactive to the major VP1 epitope (VP1230-250) of Theiler's virus: V beta restriction correlates with $\mathrm{T}$ cell recognition of the c-terminal residue. $J$. Immunol. 162: 7049-57

Kim, B. S., Yauch, R. L., Bahk, Y. Y., Kang, J. A., Dal Canto, M. C. and Hall, C. K. (1998) A spontaneous low-pathogenic variant of Theiler's virus contains an amino acid substitution within the predominant VP1(233-250) T-cell epitope. J. Virol. 72: 1020-7

Kurtz, C. I., Sun, X. M. and Fujinami, R. S. (1995) B-lymphocyte requirement for vaccine-mediated protection from Theiler's murine encephalomyelitis virus-induced central nervous system disease. J. Virol. 69: 5152-5

Lane, T. E. and Buchmeier, M. J. (1997) Murine coronavirus infection: a paradigm for virus-induced demyelinating disease [see comments]. Trends Microbiol. 5: 9-14

Lee, S. C., Liu, W., Dickson, D. W., Brosnan, C. F. and Berman, J. W. (1993) Cytokine production by human fetal microglia and astrocytes. Differential induction by lipopolysaccharide and IL-1 beta. J. Immunol. 150: 2659-67

Lin, X., Pease, L. R., Murray, P. D. and Rodriguez, M. (1998) Theiler's virus infection of genetically susceptible mice induces central nervous system-infiltrating CTLs with no apparent viral or major myelin antigenic specificity. J. Immunol. 160: 5661-8 Lindsley, M. D., Thiemann, R. and Rodriguez, M. (1991) Cyto- toxic $T$ cells isolated from the central nervous systems of mice infected with Theiler's virus. J. Virol. 65: 6612-20

Lipton, H. L. and Friedmann, A. (1980) Purification of Theiler's murine encephalomyelitis virus and analysis of the structural virion polypeptides: correlation of the polypeptide profile with virulence. J. Virol. 33: 1165-1172

Malipiero, U., Frei, K., Spanaus, K. S., Agresti, C., Lassmann, H., Hahne, M., Tschopp, J., Eugster, H. P. and Fontana, A. (1997) Myelin oligodendrocyte glycoprotein-induced autoimmune encephalomyelitis is chronic/relapsing in perforin knockout mice, but monophasic in Fas- and Fas ligand-deficient Ipr and gld mice. Eur. J. Immunol. 27: 3151-60

Massa, P. T., Dorries, R. and ter Meulen, V. (1986) Viral particles induce la antigen expression on astrocytes. Nature 320 : 543-6

McFarlin, D. E. and McFarland, H. F. (1982) Multiple sclerosis (first of two parts). N. Engl. J. Med. 307: 1183-8

Miller, S. D., Vanderlugt, C. L., Begolka, W. S., Pao, W., Yauch, R. L., Neville, K. L., Katz-Levy, Y., Carrizosa, A. and Kim, B. S. (1997) Persistent infection with Theiler's virus leads to CNS autoimmunity via epitope spreading. Nature Med. 3: 1133-1136

Montgomery, D. L. (1994) Astrocytes: form, functions, and roles in disease. Vet. Pathol. 31: 145-67

Murray, P. D., McGavern, D. B., Lin, X., Njenga, M. K., Leibowitz, J., Pease, L. R. and Rodriguez, M. (1998) Perforindependent neurologic injury in a viral model of multiple sclerosis. J. Neurosci. 18: 7306-14

Nicholson, S. M., Dal Canto, M. C., Miller, S. D. and Melvold, R. W. (1996) Adoptively transferred CD8+ T lymphocytes provide protection against TMEV-induced demyelinating disease in BALB/c mice. J. Immunol. 156: 1276-83

Nikcevich, K. M., Gordon, K. B., Tan, L., Hurst, S. D., Kroepfl, J. F., Gardinier, M., Barrett, T. A. and Miller, S. D. (1997) IFNgamma-activated primary murine astrocytes express B7 costimulatory molecules and prime naive antigen-specific $T$ cells. J. Immunol. 158: 614-21

Palma, J. P., Park, S. H. and Kim, B. S. (1996) Treatment with lipopolysaccharide enhances the pathogenicity of a low-pathogenic variant of Theiler's murine encephalomyelitis virus. $J$. Neurosci. Res. 45: 776-85

Palma, J. P., Yauch, R. L., Lang, S. and Kim, B. S. (1999) Potential role of CD4+ $\mathrm{T}$ cell-mediated apoptosis of activated astrocytes in Theiler's virus-induced demyelination. J. Immunol. 162: 6543-51

Pritchard, A. E., Jensen, K. and Lipton, H. L. (1993) Assembly of Theiler's virus recombinants used in mapping determinants of neurovirulence. J. Virol. 67: 3901-7

Pullen, L. C. and Kim, B.S. (1991) Identification of a suitable target cell line for Theiler's murine encephalomyelitis virus specific CTL. Faseb. J. 75: 150

Pullen, L. C., Miller, S. D., Dal Canto, M. C., Van der Meide, P. H. and Kim, B. S. (1994) Alteration in the level of interferongamma results in acceleration of Theiler's virus-induced 
demyelinating disease. J. Neuroimmunol. 55: 143-52

Pullen, L. C., Park, S. H., Miller, S. D., Dal Canto, M. C. and Kim, B. S. (1995) Treatment with bacterial LPS renders genetically resistant C57BL/6 mice susceptible to Theiler's virusinduced demyelinating disease. J. Immunol. 155: 4497-503

Rieckmann, P., Albrecht, M., Kitze, B., Weber, T., Tumani, H., Broocks, A., Luer, W., Helwig, A. and Poser, S. (1995) Tumor necrosis factor-alpha messenger RNA expression in patients with relapsing-remitting multiple sclerosis is associated with disease activity. Ann. Neurol. 37: 82-8

Rivera-Quinones, C., McGavern, D., Schmelzer, J. D., Hunter, S. F., Low, P. A. and Rodriguez, M. (1998) Absence of neurological deficits following extensive demyelination in a class $\mathrm{I}$ deficient murine model of multiple sclerosis. Nature Med. 4: 187-93

Rodriguez, M., Lafuse, W. P., Leibowitz, J. and David, C. S. (1986) Partial suppression of Theiler's virus-induced demyelination in vivo by administration of monoclonal antibodies to immune-response gene products (la antigens). Neurology. 36: 964-970

Rodriguez, M., Pavelko, K. and Coffman, R. L. (1995) Gamma interferon is critical for resistance to Theiler's virus-induced demyelination. J. Virol. 69: 7286-90

Sabelko, K. A., Kelly, K. A., Nahm, M. H., Cross, A. H. and Russell, J. H. (1997) Fas and Fas ligand enhance the pathogenesis of experimental allergic encephalomyelitis, but are not essential for immune privilege in the central nervous system. J. Immunol. 159: 3096-9

Sato, S., Zhang, L., Kim, J., Jakob, J., Grant, R. A., Wollmann, R. and Roos, R. P. (1996) A neutralization site of DA strain of Theiler's murine encephalomyelitis virus important for disease phenotype. Virology 226: 327-37

Shrikant, P., Weber, E., Jilling, T. and Benveniste, E. N. (1995) Intercellular adhesion molecule-1 gene expression by glia cells. Differential mechanisms of inhibition by IL-10 and IL-6. J. Immunol. 155: 1489-501

Smyth, J. M., Sheahan, B. J. and Atkins, G. J. (1990) Multiplication of virulent and demyelinating Semliki Forest virus in the mouse central nervous system: consequences in BALB/C and SJL mice. J. Gen. Virol. 71: 2575-83

Soldan, S. S., Berti, R., Salem, N., Secchiero, P., Flamand, L., Calabresi, P. A., Brennan, M. B., Maloni, H. W., McFarland, H. F., Lin, H. C., Patnaik, M. and Jacobson, S. (1997) Association of human herpes virus 6 (HHV-6) with multiple sclerosis: increased lgM response to HHV-6 early antigen and detection of serum HHV-6 DNA [see comments]. Nature Med. 3: 1394-7

Tani, M., Glabinski, A. R., Tuohy, V. K., Stoler, M. H., Estes,
M. L. and Ransohoff, R. M. (1996) In situ hybridization analysis of glial fibrillary acidic protein mRNA reveals evidence of biphasic astrocyte activation during acute experimental autoimmune encephalomyelitis. Am. J. Pathol. 148: 889-96

Theiler, M. and Gard, S. (1940) Encephalomyelitis of mice. J. Exp. Med. 72: 49-67

Wada, Y., Pierce, M. L. and Fujinami, R. S. (1994) Importance of amino acid 101 within capsid protein VP1 for modulation of Theiler's virus-induced disease. J. Virol. 68: 1219-23

Waldner, H., Sobel, R. A., Howard, E. and Kuchroo, V. K. (1997) Fas- and FasL-deficient mice are resistant to induction of autoimmune encephalomyelitis. J. Immunol. 159: 3100-3

Welsh, C. J., Tonks, P., Nash, A. A. and Blakemore, W. F. (1987) The effect of L3T4 T cell depletion on the pathogenesis of Theiler's murine encephalomyelitis virus infection in CBA mice. J. Gen. Virol. 68: 1659-1667

Wesselingh, S. L., Gough, N. M., Finlay-Jones, J. J. and McDonald, P. J. (1990) Detection of cytokine mRNA in astrocyte cultures using the polymerase chain reaction. Lymphokine Res. 9: 177-85

Wisniewski, H. M. and Bloom, B. R. (1975) Primary demyelination as a nonspecific consequence of a cell-mediated immune reaction. J. Exp. Med. 141: 346-59

Wong, G. H., Bartlett, P. F., Clark-Lewis, I., Battye, F. and Schrader, J. W. (1984) Inducible expression of H-2 and la antigens on brain cells. Nature 310: 688-91

Yahikozawa, H., Inoue, A., Koh, C. S., Choe, Y. K. and Kim, B. S. (1997) Major linear antibody epitopes and capsid proteins differentially induce protective immunity against Theiler's virus-induced demyelinating disease. J. Virol. 71: 3105-13

Yauch, R. L., Kerekes, K., Saujani, K. and Kim, B. S. (1995) Identification of a major T-cell epitope within VP3 amino acid residues 24 to 37 of Theiler's virus in demyelination-susceptible SJL/J mice. J. Virol. 69: 7315-8

Yauch, R. L. and Kim, B. S. (1994) A predominant viral epitope recognized by $T$ cells from the periphery and demyelinating lesions of SJL/J mice infected with Theiler's virus is located within VP1(233-244). J. Immunol. 153: 4508-19

Yauch, R. Y., Palma, J. P., Yahikozawa, H., Koh, C.-S. and Kim, B. S. (1998) Role of individual T cell epitopes of Theiler's virus in the pathogenesis of demyelination correlates with the ability to induce a Th1 response. J. Virol. 72: 6169-6174

Zurbriggen, A. and Fujinami, R. S. (1989) A neutralizationresistant Theiler's virus variant produces an altered disease pattern in the mouse central nervous system. J. Virol. 63: 1505-1513 